\title{
PENGARUH JUMLAH PENDUDUK DAN PDRB TERHADAP KEMISKINAN DI PROVINSI SUMATERA UTARA
}

\author{
Oleh: \\ Rapika Kesatriani Damanik ${ }^{1)}$ \\ Selna Aprilia Sidauruk ${ }^{2}{ }^{*}$ \\ Universitas Negeri Medan ${ }^{1,2)}$ \\ E-mail: \\ rapikadamanik01@gmail.com ${ }^{1)}$ \\ dansyelna0400@gmail.com²)
}

\begin{abstract}
Poverty is a problem in development. With the existence of poverty, development is hampered. The factors causing poverty include population and GDP. This study aims at determining the effect of population and GDP on poverty in North Sumatra in 2008-2017 so that the bias is used as a basis for determining policies and strategies in overcoming poverty in North Sumatra. The data used in this study is secondary data obtained from the Central Statistics Agency (BPS) while the data analysis technique used in this study is multiple linear regression analysis with the help of SPSS 24. The results show that the population and GRDP had a significant effect on poverty in North Sumatra.
\end{abstract}

Keywords: Poverty, Population, and GDP

\begin{abstract}
ABSTRAK
Kemiskinan merupakan salah satu variabel dalam ekonomi yang memperlambat pembangunan. Dengan adanya kemiskinan pembangunan menjadi terhambat. Faktor yang menyebabkan kemiskinan terjadi diantaranya adalah jumlah penduduk dan PDRB. Oleh karena itu, penelitian ini sangat penting dilakukan untuk melihat bagaimana pengaruh jumlah penduduk dan PDRB terhadap kemiskinan di Provinsi Sumatera Utara tahun 2008-2017, sehingga dapat dijadikan sebagai dasar dalam penentuan kebijakan dan strategi dala mengatasi kemiskinan di Provinsi Sumatera Utara. Dalam penelitian ini, data yang diolah untuk mendapatkan informasi tentang variabel yang diteliti yaitu data sekunder oleh BPS (Badan Pusat Statistika). Sedangkan analisis regresi linear berganda merupakan teknik analisis data dalam penelitian ini yang digunakan dalam menganalisis data yang telah diolah menggunakan SPSS 24. Hasil yang diperoleh dalam penelitian ini menjelaskan bahwa variabel jumlah penduduk dan PDRB berpengaruh signifikan terhadap variabel kemiskinan di provinsi Sumatera Utara tahun 2008-2017
\end{abstract}

Kata Kunci: Kemiskinan, Jumlah Penduduk, dan PDRB 


\section{PENDAHULUAN}

Kesejahteraan masyarakat merupakan tujuan akhir pemb angu nan nasional. Adanya pembangunan dapat menunjukkan perubahan kehidupan masyarakat mencapai tahapan yang lebih baik. Hal ini sejalan dengan pendapat Sukmaraga (2011) bahwa pembangunan adalah suatu proses perubahan menuju ke arah yang lebih baik dan continue dalam mewujudkan masyarakat yang modern, maju dan sejahtera dalam Negara Kesatuan Republik Indonesia.

Dalam mewujudkan pembangunan, factor penghambat pembangunan sangat penting untuk diperhatikan agar semua pihak dapat mengatasi hal tersebut. salah satu factor yang menghambat pembangunan yaitu kemiskinan. Menurut Kuncoro (2009) bahwa kemiskinan adalah ketidakmapuan memenuhi standar hidup minimum. Kemiskinan merupakan masalah yang sulit di atasi dalam pembangunan suatu negara terutama bagi negera berkembang, seperti Indonesia. Kemiskinan memiliki konsep yang fleksibel sesuai dengan perkembangan peradaban manusia.

Makna kemiskinan itu juga merupakan keadaan dimana individu atau masyarakat dalam suatu negara tidak dapat memenuhi kebutuhan hidupnya, seperti sandang dan pangan.

Selain sandang dan pangan, pendidikan, kesehatan, dan pendapatan juga merupakan indikator seseorang atau masyarakat dikatakan miskin. Bahkan saat ini kemiskinan telah memiliki standarnya. Standar kemiskinan yang selalu berubah sesuai dengan perkembangan peradaban manusia. Standar kemiskinan pada saat ini berbeda dengan standar kehidupan sebelumnya ketika kemiskinan itu dianggap hanya tidak memiliki sand ang dan pangan. Namun pada saat ini, standar kemiskinan itu diukur melalui garis kemiskinan yang kriterianya kian bertambah banyak.

Menurut Sastraadmadja (dalam Permana:2012) bahwa berdasarkan pola waktu, kemiskinan dibedakan menjadi 4, antara lain: a) Persistent Poverty, y aitu kemiskinan yang kronis atau turun temurun, b) Cylical Poverty, yaitu kemiskinan yang yang mengikuti pola siklus ekonomi secara keseluruhan, c) Seasonal Poverty, yaitu kemiskinan musiman yang sering dijumpai pada kasus nelayan dan pertanian, dan d) Accident Poverty, yaitu kemiskinan yang tercipta karena adanya bencana alam, konflik dan kekerasan, atau damapk dari suatu kebijakan tertentu yang menyebabkan menurunnya tingkat kesejahteraan suatu masyarakat.

Kemiskinan memiliki peranan penting dalam menentukan keberhasilan pembangunan suatu negara. Sejalan dengan hal tersebut, kemiskinan menjadi masalah yang sangat memiliki kaitan erat dengan pembangunan. Semakin kecil angka kemiskinan dalam suatu negara, maka pembangunan negara tersebut akan lebih baik. Sebaliknya, semakin tinggi angka kemiskinan suatu negara, maka pembangunan akan sulit untuk berkembang menjadi lebih baik. Hal ini karena sasaran dari pembangunan dan kemiskinan tersebut sama, yaitu masyarakat sehingga adanya kemiskinan ini tentu sangat meresahkan bagi semua pihak, baik individu, masyarakat, dan pemerintah.

Oleh karena itu, dapat dikatakan bahwa kemiskinan merupakan masalah 
yang kronis dan sangat penting untuk dikaji agar pemerintah dalam suatu negara dapat melihat perkembangan kemiskinan tersebut, antara lain sejauh mana dampak kemiskinan tersebut bagi pembangunan serta membantu pemerintah bagaimana kebijakan dan strategi apa yang harus dilakukan dalam memutuskan rantai kemiskinan melalui evaluasi kebijakan dan strategi yang telah dilakukan dalam memutuskan rantai kemiskinan tersebut. Banyak faktor yang mempengaruhi tingkat kemiskinan, antara lain jumlah penduduk, pengangguran, PDRB, dan pendidikan.

Salah satu faktor penyebab kemiskinan yang diteliti dalam penelitian ini yaitu jumlah penduduk. Siregar dan Wahuniarti (2008) menyatakan bahwa apabila jumlah penduduk semakin banyak, maka akan meningkatkan jumlah penduduk miskin . Penduduk yang dimaksud yaitu mereka orang yang yang menetap dan bertempat tinggal di wilayah tertentu. bertambahnya jumlah penduduk dipengaruhi oleh fertilitas, mortalitas, dan migrasi. Jumlah penduduk yang meningkat akan menimbulkan banyaknya jumlah angkatan kerja.

Banyaknya angkatan kerja tetapi tidak diimbangi dengan jumlah lapangan pekerjaan mengakibatkan banyak angkatan kerja yang menganggur sehingga menyebabkan pengangguran yang menimbulkan kemiskinan. Oleh karena itu, semakin banyak jumlah penduduk maka kemiskinan juga semakin tinggi angkanya terutama bagi negara berkembang. Untuk itu, pemerintah selalu menekan laju pertumbuhan penduduk dengan kebijakan-kebijakannya, seperti program Keluarga Berencana(KB).
Selain jumlah penduduk factor yang mempengaruhi kemiskinan yang diteliti dala penelitian ini adlah PDRB. PDRB suatu wilayah yang tinggi menandakan wilayah tersebut memeiliki perekonoman yang baik. Sebaliknya, PDRB suatu wilayah yang rendah menandakan perekonomian wilayah tersebut tidaklah dalam keadaan baik. Perekonomian yang dimaksud yaitu perekonomian yang dapat menunjang kehidupan masyarakat sehingga tidak terjadi kemiskinan. PDRB suatu wilayah tinggi apabila wilayah tersebut dapat mengoptimalkan potensi wilayahnya sendiri dengan memanfaatkan sarana dan prasarana yang memadai. PDRB yang tinggi akan menekan tingkat kemiskinan, karena dengan tingginya PDRB pembangunan dapat dioptimalkan, sehingga tercapai kesejahteraan masyarakat. Sebaliknya, PDRB yang rendah akan meningk atkan jumlah kemiskinan dalam masyarakat, karena pembangunan yang dilakukan dalam menyejahterakan masyarakat tidak optimal.

Berdasarkan data sekunder yang diperoleh penulis dari BPS, jumlah penduduk miskin di Provinsi Sumatera Utara mengalami perubahan dari tahun 2008 sampai 2017 secara fluktuasi yang ditunjukkan oleh tabel berikut.

Tabel 1 Jumlah Penduduk Miskin Provinsi Sumatera Utara Tahun 20082017

\begin{tabular}{|c|c|}
\hline Tahun & $\begin{array}{c}\text { Penduduk } \\
\text { Miskin (Jiwa) }\end{array}$ \\
\hline 2008 & 1.630 .000 \\
\hline 2009 & 1.500 .000 \\
\hline 2010 & 1.490 .000 \\
\hline 2011 & 1.436 .400 \\
\hline 2012 & 1.400 .400 \\
\hline
\end{tabular}




\begin{tabular}{|c|c|}
\hline 2013 & 1.416 .400 \\
\hline 2014 & 1.360 .600 \\
\hline 2015 & 1.508 .140 \\
\hline 2016 & 1.452 .600 \\
\hline 2017 & 1.326 .600 \\
\hline \multicolumn{2}{|c|}{ Sumber: Badan Pusat Statistika }
\end{tabular}

Dari data di atas dapat dilihat bahwa penduduk miskin di Sumatera Utara jumlahnya tidak stabil. Ketidakstabilan jumlah penduduk miskin ditunjukkan pada tahun 2008 sampai 2017 jumlah penduduk miskin menurun dari 1.630.000 jiwa pada tahun 2008 menjadi 1.40 .400 jiwa pada tahun 2012. Kemudian, jumlah penduduk meningkat pada tahun 2013 sebesar 1.416.400 jiwa dari tahun 2012 dan turun pada tahun 2017 menjadi 1.360.600 jiwa. Dan dari tahun 2015 sapai tahun 2017 jumlah penduduk miskin menurun dari 1.508.140 jiwa menjadi 1.326 .600 jiwa. Tentunya jumlah kemiskinan yang tidak stabil ini dipengaruhi oleh beberapa factor, diantaranya Jumlah Penduduk dan PDRB.

Berdasarkan data sekunder yang diperoleh penulis dari BPS, jumlah penduduk Provinsi Sumatera Utara tahun 2008 sampai 2017 terus mengalami peningkatan yang diuraikan dalam tabel berikut.

Tabel 2 Jumlah Penduduk Provinsi Sumatera Utara tahun 2008-2017

\begin{tabular}{|c|c|}
\hline Tahun & $\begin{array}{c}\text { Penduduk } \\
\text { (Jiwa) }\end{array}$ \\
\hline 2008 & 12.834 .371 \\
\hline 2009 & 13.042 .317 \\
\hline 2010 & 13.248 .386 \\
\hline 2011 & 12.982 .204 \\
\hline 2012 & 13.103 .596 \\
\hline 2013 & 13.215 .401 \\
\hline
\end{tabular}

\begin{tabular}{|l|l|}
\hline 2014 & 13.326 .307 \\
\hline 2015 & 13.766 .851 \\
\hline 2016 & 13.937 .797 \\
\hline 2017 & 14.102 .911 \\
\hline
\end{tabular}

Sumber: Badan Pusat Statistika

Data jumlah penduduk Provinsi Sumatera Utara tersebut menunjukkan bahwa laju pertumbuhan penduduk terus mengalami peningkatan dalam kurun waktu 10 tahun yaitu dari tahun 20081017. Meningkatnya jumlah penduduk ini yakni dari 12.834.371 jiwa pada tahun 2008 menjadi 14.102.911 jiwa tahun 2017 menunjukkan tingginya angka keahiran dan banyaknya migrasi masuk ke Provinsi Sumatera Utara dibandingkan jumlah mortalitas. Hal ini tentu berdampak bagi peningkatan jumlah penduduk miskin.

Jumlah penduduk tersebut memberikan kontribusi yang sangat besar terhadap tingkat kemiskinan, dimana semakin banyak jumlah penduduk dalam suatu negara terutama bagai negara berkembang, maka angka kemiskinan akan bertambah. Pertumbuhan ekonomi belum dalam suatu wilayah belum tentu menjamin apakan induvidu telah sejahtera atau tidak. Namun dengan adanya pertumbuhan ekonom tersebut mampu membantu individu keluar dari kemiskinan secara tidka langsung. Untuk itu jika jemlah penduduk dalam suatu wilayah tinggi meskipun pertumbuhan ekonomi tinggi tidak menjadi jaminan masyarakat sejahtera dan keluar dari garis kemiskinan.

Pertumbuhan ekonomi memberi kontribusi bagi pembangunan daerah. Pertumbuhan ekonomi suatu daerah dicerminkan dari PDRB daerah tersebut (Suryono:2010). Pertumbuhan ekonomi dilihat dari dilihat dari besarnya 
produksi barang dan jasa yang dilakukan suatu wilayah dalam meningkatkan perekonomannya yang dilihat dari dari subsektor yang telah ditetapkan.

Semakin tinggi PDRB suatu daerah maka pembangunan daerah tersebut akan lebih baik yang secara tidak langsung dapat mengurangi an gka kemiskinan. Hal ini dapat terjadi karena dengan tingginya PDRB suatu daerah, maka daerah tersebut dapat memperbaiki sarana dan prasarana daerahnya sehingga dapat menunjang perekonomiannya. Selain itu PDRB daerah yang tinggi juga akan membantu masyarakat yang menganggur melalui lapangan pekerjaan yang mampu diciptakan daerah tersebut dalam mengoptimalkan potensi daerahnya baik potensi alamnya, modal, dan sebagainya.

Berdasarkan data sekunder yang diperoleh penulis dari BPS, PDRB Provinsi Sumatera Utara dari tahun 2008 sapai 2017

Tabel 3 PDRB Provinsi Sumatera Utara Tahun 2008-2017

\begin{tabular}{|c|c|}
\hline Tahun & PDRB (Miliyar Rp) \\
\hline 2008 & $195.155,20$ \\
\hline 2009 & $326.353,60$ \\
\hline 2010 & $275.056,50$ \\
\hline 2011 & $314.372,40$ \\
\hline 2012 & $417.120,20$ \\
\hline 2013 & $469.460,20$ \\
\hline 2014 & $521.920,90$ \\
\hline 2015 & $571.720,30$ \\
\hline 2016 & $628.390,80$ \\
\hline 2017 & $684.072,70$ \\
\hline
\end{tabular}

Berdasarkan tabel di atas, dapat dilihat PDRB Provinsi Sumatera Utara dari tahun 2008 sapai 2017 mengalami peningkatan kecuali pada tahun $2009 \mathrm{ke}$ tahun 2010 dimana terjadi penurunan PDRB dari 326.353,60 miliyar menja di 275.056,50 milyar. Meningkatnya PDRB provinsi Sumatera Utara ini menjelaskan bahwa pertumbuhan ekonom Sumatera Utara meningkat. Meningkatnya PDRB ini mempengaruhi jumlah penduduk yang miskin di Provinsi Sumatera Utara. Pertumbuhan ekonomi yang meningkat akan merdampak pada pembangunan Sumatera Utara menuju arah lebih baik dan tentunya mengurangi angka kemiskinan di Sumatera Utara.

\section{TINJAUAN PUSTAKA}

\section{Kemiskinan}

Ada banyak defenisi dan konsep mengenai kemiskinan. Bank dunia (2000) mengartikan bahwa kemiskinan adalah kekurangan, yang sering diukur dengan tingkat kesejahteraan. Sementara itu, Kuncoro (2006) menyatakan b ahwa kemiskinan adalah ketidakmampuan untuk memenuhi standar hidup minimum. Kebutuhan yang harus dipenuhi tersebut terdiri dari sandang, pangan, pendidikan, papan, dan kesehatan. Kemudian Kuncoro (2006) juga menyatakan bahwa kemiskinan itu setidaknya dapat dilihat dari dua sisi, yaitu: pertama, kemiskinan absolut, dimana dengan pendekatan ini diidentifikasi jumlah penduduk yang hidup di bawah garis kemiskinan tertentu. kedua, kemiskinan relatif, yaitu pangsa pendapatan nasional yang diterima oleh masing-masing golongan pendapatan. Dengan kata lain, kemiskinan relative amat erat kaitan nya dengan masalah distribusi pendapatan.

Kemudian, menurut Badan Pusat Statistika (dalam Maipita,dkk :2010) bahwa kemiskinan yaitu 
seseorang tergolong dala kategori miskin bila ia tidak mapu memenuhi kebutuhan dasarnya (basic needs), dengan kata lain kemiskinan dipandang sebagai ketidakmampuan dari sisi ekonomi dalam memenuhi kebutuhan dasar, baik makanan maupun non makanan yang diukur dari sisi pengeluaran.

Kemiskinan merupakan masalah yang sangat penting untuk diperhatikan. Kemiskinan dalam suatu negara dipengaruhi oleh banyak factor. Menurut Sharp(dalam Kuncoro :2006) terdapat tiga factor penyebab kemiskinan, y aitu: a) kemiskinan muncul karena tidak adanya kesamaan pola kepemilikan sumber daya yang menimbulkan distribusi pendapatan yang timpang. b) kemiskinan muncul akibat perbedaan dalam kualitas sumberdaya manusia. c) kemiskinan muncul karena perbedaan akses dan modal.

Kemiskinan dalam suatu negara memiliki kategori yang sesuai dengan ketentuan yang dianut oleh negara tersebut. terdapat tiga Kategori kemiskinan menurut Maipita, $\operatorname{dkk}(2010)$ antara lain: a) kemiskinan structural, kategori jenis ini umumnya disebabkan oleh tatanan kelembagaan dan sistem yang diterapkan, seperti sistem politik, ekonomi, keamanan dan lainnya dan oleh karenannya kondisi social ek onom masyarakat menjadi rendah atau tidak mungkin sejahtera, b) kemiskinan kultural, yaitu kemiskinan yang disebabkan oleh budaya penduduk yang malas, tidak mau kerja keras, jadi etos bekerjanya sangat rendah, tidak disiplin dan sebagainya, c) kemiskinan ab solut, yaitu kemiskinan yang dipandang dari sisi kemampuan memenuhi kebutuh an dasar minimum. Biasanya didasarkan pada sejumlah nutrisi. Kemiskinan absolut sering juga disebut dengan kemiskinan primer, bahkan disebut dengan kemiskinan ekstrim.

\section{Jumlah Penduduk}

Badan Pusat Statistika (2013) menartikan bahwa jumlah penduduk adalah semua orang yang berdomisili di wilayah geografis Republik Indonesia selama 6 bulan atau lebih dan atau mereka yang berdomisisli kurang dari 6 bulan tetapi bertujuan untuk menetap. Sementara itu, Said (2012) mendefenisikan bahwa penduduk adalah jumlah yang bertempat tinggal di suatu wilayah pada waktu tertentudan merupakan hasil dari proses-proses demografi yaitu fertilitas, mortalitas, dan migrasi.

Dalam pertumbuhan penduduk terdapat 3 faktor yang mendorong pertumbuhan penduduk pada suatu wilayah, antara lain: a) fertilitas, yaitu jumlah bayi yang dilahirkan oleh seorang wanita, b) mortalitas, yaitu seseorang yang tidak memiliki tandatanda kehidupan yaitu bernafas dalam dirinya dan c) migrasi yaitu perpindahan penduduk dari suatu wilayah ke wilayah lain.

\section{PDRB}

Badan Pusat Statistika mengartikan bahwa PDRB merupakan jumlah keseluruhan dari nilai tambah barang dan jasa atau nilai akhir dari barang dan jasa yang diproduksi oleh seluruh unit usaha dalam suatu daerah . Sedangkan Nanga (2005) menyatakan bahwa PDRB adalah total nilai atau harga pasar (market place) dari seluruh barang dan jasa akhir(final goods and service) yang dihasilkan oleh suatu perekonomian selama kurun waktu tertentu. kemudian, Sukirno (2006) menyatakan bahwa laju pertumbuhan ekonomi adalah kenaikan PDRB tanpa 
memandang apakah kenaikan itu lebih besar atau lebih kecil yang pengururannya tidak hanya berdasarkan jumlah PDRB secara keseluruhan, namun juga memperlihatkan distribusi pendapatan menyebar yang telah menyebar ke seluruh lapisan dalam masyarakat.

Tinggi rendahnya angka PDRB suatu daerah ditentukan oleh kemampuan daerah tersebut dalam mengelola sumberdaya daerahnya. Hal ini sejalan dengan pendapat Permata (2012) yang menyatakan bahwa besaran PDRB yang dihasilkan oleh masingmasing daerah sangat bergantung pada potensi faktor-faktor produksi di daerah tersebut. dalam menghitung PDRB suatu daerah dapat menggunakan tiga pendekatan, antara lain: a)pendekatan produksi, b) Pendekatan Pengeluaran, c) Pendekatan pendapatan.

\section{METODE PELAKSANAAN}

Dalam penelitian ini, penulis menggunakan 3 variabel, yaitu kemiskinan Provinsi Sumatera Utara tahun 2008-2017 sebagai variabel terikat (Y) dan variabel bebasnya (X) yaitu jumlah penduduk Provinsi Sumatera Utara tahun 2008-2017 (X1) dan PDRB Provinsi Sumatera Utara tahun 20082017 (X2). Sedangkan penelitian deskriptif kualitatatif digunakan untuk menganalisis informasi jenis penelitian deskriptif kuantitatif(data yang dapat diukur) dala penelitian ini. penelitian deskriptif kuantitatif yang digunakan adalah model analisis regresi linear berganda dengan menggunakan data kemiskinan, jumlah penduduk, dan PDRB provinsi Sumatera Utara tahun 2008-2017 dari BPS.

\section{Teknik Pengumpulan Data}

Teknik pengumpulan data yang dilakukan dalam penelitian ini yaitu dengan metode dokumentasi. Teknik pengumpulan data dengan dokumentasi dalam penelitian ini yaitu pengumpulan data data tentang kemiskinan, jumlah penduduk, dan PDRB yang diperoleh dari BPS.

\section{Metode analisis}

Penelitian ini menggunakan analisis regresi linear berganda sebagai alat untuk menganalisis data yang diolah dengan program SPSS 24. Model yang dipakai dalam menjelaskan penelitian ini menggunakan persamaan :

$$
\begin{aligned}
& \mathrm{Y}=\mathrm{f}(\mathrm{X} 1, \mathrm{X} 2) \\
& \mathrm{Y}=\alpha+\beta 1 \mathrm{X} 1+\beta 2 \mathrm{X} 2+\mathrm{t} \\
& \mathrm{Y}=\alpha+\mathrm{JPX} 1+\mathrm{PDRBX} 2+\mathrm{t}
\end{aligned}
$$

\section{HASIL DAN PEMBAHASAN}

Data yang diperoleh dari BPS diuji menggunakan uji asumsi klasik dengan guna mendapatkan hasil yang baik. Setelah uji asumsi klasik dilakukan kemudian data dianalisis menggunakan teknik analisis regresi linear berganda serta melakukan uji hipotesis untuk melihat pengaruh antara variable terikat terhadap variable bebas serta menentukan koefisien determinasi untuk melihat sebesapa besar kontribusi variabel bebas terhadap variabel terikat.

\section{Uji Asumsi Klasik}

Sebelum melakukan pengujian hipotesis dalam penelitian ini, akan dilakukan uji asumsi klasik terlebih dahulu. uji asumsi klasik tersebut terdiri dari uji normalitas, uji heterokedastisitas, uji autokorelasi, uji multikolinearitas, dan uji linearitas.

a. Uji Normalitas 
Salah satu pengujian yang dilakukan dalam asumsi klasik yaitu normalitas. Pengujian ini dilakukan untuk mengetahui variabel yang diteliti dalam keadaan normal atau tidak.

Tabel 4 Hasil Uji Normalitas

\begin{tabular}{|c|c|c|}
\hline & & Unstandardized Residual \\
\hline \multicolumn{2}{|l|}{$\mathrm{N}$} & (2) \\
\hline \multirow[t]{2}{*}{ Normal Parameters } & Mean & .0000000 \\
\hline & Std. Deviation & 56825.33198000 \\
\hline \multirow[t]{3}{*}{ Most Extreme Differences } & Absolute & .164 \\
\hline & Positive & .164 \\
\hline & Negative & -.117 \\
\hline \multicolumn{2}{|l|}{ Test Statistic } & .164 \\
\hline \multicolumn{2}{|l|}{ Asymp. Sig. (2-tailed) } & $.200^{\mathrm{c}, \mathrm{d}}$ \\
\hline \multicolumn{3}{|c|}{ Sumber: Output SPSS 24} \\
\hline \multicolumn{2}{|c|}{$\begin{array}{l}\text { Tabel di atas merupakan hasil } \\
\text { olahan SPSS } 24 \text { yang menunjukkan nilai } \\
\text { asymp. Sig ( } 2 \text {-tailed) sebesar } 0,200 \text {. } \\
\text { Apabila sig }>0,05 \text { maka penelitian } \\
\text { normal. Berdasarkan hal tersebut, dapat } \\
\text { ditarik kesimpulan bahwasanya sig = }\end{array}$} & $\begin{array}{l}>0,05 \text {, menjelaskan bahwa data } \\
\text { penelitian ini berdistribusi } \\
\text { Heterokedastisitas } \\
\text { Uji heterokedastisitas digunakan } \\
\text { melihat ada atau tidaknya gejala } \\
\text { kedastisitas dalam model regresi. }\end{array}$ \\
\hline
\end{tabular}

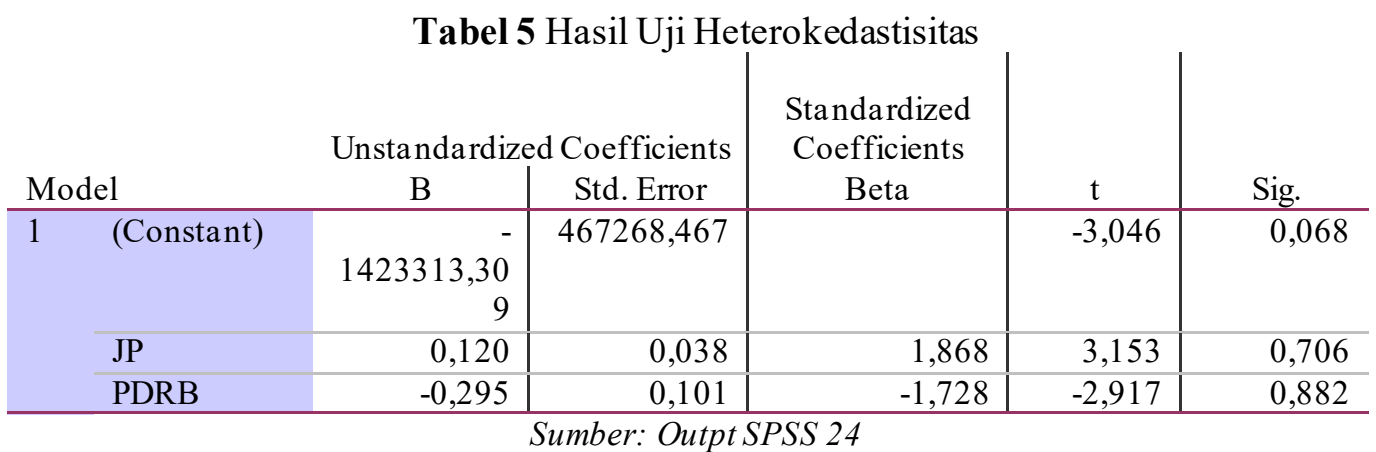

Tabel di atas menunjukkan bahwa nilai sig. jumlah penduduk sebesar $0,706>0,05$ sedangkan nilai sig. PDRB sebesar $0,882>0,05$,. Hal ini menunjukkan bahwa variabel jumlah penduduk dan PDRB bebas dari gejala heterokedastisitas.

c. Uji Autokorelasi

uji autokorelasi digunakan untuk mendeteksi ada atau tidaknya gejala autokorelasi dalam model regresi.

\begin{tabular}{|c|c|c|c|c|c|}
\hline \multirow[b]{2}{*}{ Model } & \multicolumn{4}{|c|}{ Tabel 6 Hasil Uji Autokorelasi } & \multirow[b]{2}{*}{$\begin{array}{l}\text { Durbin- } \\
\text { Watson }\end{array}$} \\
\hline & $\mathrm{R}$ & $\begin{array}{c}\mathrm{R} \\
\text { Square }\end{array}$ & $\begin{array}{l}\text { Adjusted R } \\
\text { Square }\end{array}$ & $\begin{array}{l}\text { Std. Error of the } \\
\text { Estimate }\end{array}$ & \\
\hline 1 & $.752^{\mathrm{a}}$ & 0,565 & 0,441 & 64433,870 & 1,418 \\
\hline
\end{tabular}


Tabel di atas meunjukkan bahwa nilai Durbin Watson (d) sebes ar $1,418>$ du yaitu $1,401<(4-$ du $)$ yaitu 2,599 . Hal ini menunjukkan bahwa dalam data tersebut tidak terdapat gejala autokorelasi. d. Uji Multikolinearitas

Uji multikolinearitas dilakukan untuk mengetahui hubungan antar variable bebas dan terikat dimana umumnya nilai korelasi mendekati 1 .

Tabel 7 Hasil Uji Multikolinearitas

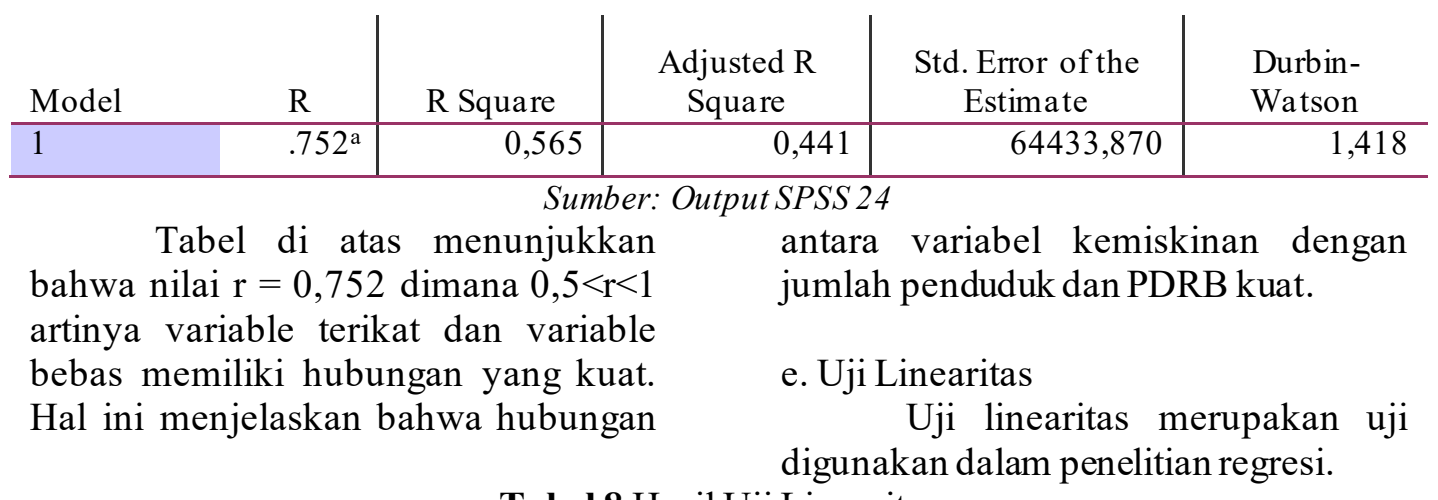

Tabel 8 Hasil Uji Linearitas

\begin{tabular}{ll|r|r|r|c} 
& Sum of Squares & Df & Mean Square & F & Sig. \\
\hline 1 & 4536353272.000 & 10 & 18887132230.000 & 15.000 & $.504^{\mathrm{b}}$ \\
\hline $\begin{array}{l}\text { Combinated } \\
\text { Linearity }\end{array}$ & 76345726430.000 & 2 & 4151723598.000 & 7.100 & .000 \\
\hline $\begin{array}{l}\text { Deviation of } \\
\text { Linearity }\end{array}$ & 66836329640.000 & 8 & 53.796 & 4,498 & .721 \\
& & & & & \\
\hline
\end{tabular}

Sumber: Output SPSS 24

Berdasarkan tabel di atas dapat dilihat bahwa nilai $\mathrm{F}_{\text {hitung }}=4,549$ dan sig. sebesar 0,721>0,05 menunjukkan bahwa kelompok data yang diolah dalam penelitian ini linear.

Analisis Regresi Linear Berganda

Tabel 9 Hasil Estimasi

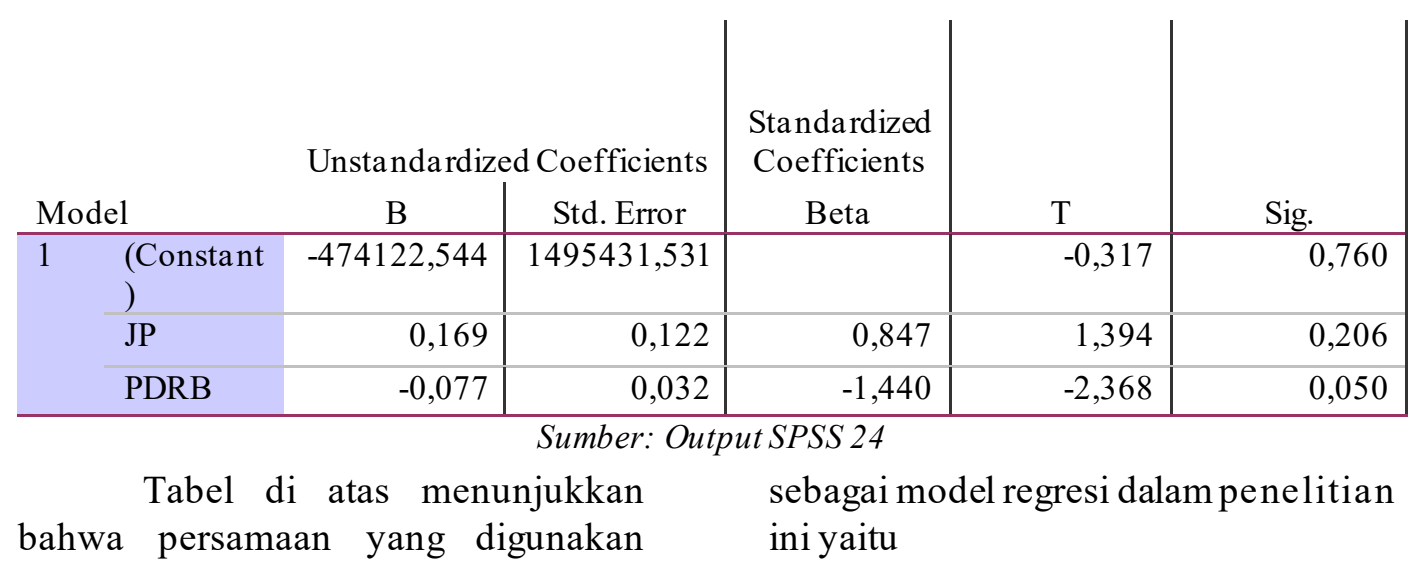


$\mathrm{Y}=-474122,544+0,169 \mathrm{X} 1-0,077 \mathrm{X} 2+$ $\mu$

Pada tabel di atas juga menunjukkan bahwa dalam uji hipotesis yaitu uji t menunjukkan bahwa nilai $t$ hitung sebesar 1,394 > nilai $\mathrm{t}$ tabel sebesar 0,711 pada variable jumlah penduduk. Hal ini menjelaskan bahwa variabel jumlah penduduk memiliki pengaruh yang positif dan signifikan terhadap variable kemiskinan. Selain itu, pada tabel tersebut menunjukkan bahwa nilai thitung sebesar 2,368 $>$ nilai t tabel sebesar 0,711 pada variable PDRB. Hal ini menjelaskan bahwa variable PDRB memiliki pengaruh yang negative dan signifikan terhadap variabel kemiskinan.

Sedangkan untuk uji hipotesis y aitu uji $\mathrm{F}$ (simultan) dapat dilihat dari tabel berikut.

Tabel 10 Anova

\begin{tabular}{llr|r|r|r|c} 
Model & Sum of Squares & Df & Mean Square & F & Sig. \\
\hline 1 & Regression & 37774264450.000 & 2 & 18887132230.000 & 4.549 & $.054^{\mathrm{b}}$ \\
\cline { 2 - 6 } & Residual & 29062065190.000 & 7 & 4151723598.000 & & \\
\hline Total & 66836329640.000 & 9 & & & \\
\hline \multicolumn{6}{c}{ Sumber: Output SPSS 24 }
\end{tabular}

Pada tabel di atas menunjukkan bahwa nilai $F$ hitung sebesar 4,549 dengan sig. sebesar 0,05 . Hal ini menjelaskan bahwa $\mathrm{F}$ hitung $>$ Ftabel yaitu 4,549>4,460 artinya variabel jumlah penduduk dan variabel PDRB secara simultan memiliki pengaruh yang signifikan terhadap variabel kemiskinan.

Koefisien Determinasi

\begin{tabular}{lc|c|c|c|c} 
& \multicolumn{2}{c}{ Tabel 11 Koefisien Determinasi } \\
Model & R & R Square & $\begin{array}{c}\text { Adjusted R } \\
\text { Square }\end{array}$ & $\begin{array}{c}\text { Std. Error of the } \\
\text { Estimate }\end{array}$ & $\begin{array}{c}\text { Durbin- } \\
\text { Watson }\end{array}$ \\
\hline 1 & $.752^{\mathrm{a}}$ & 0,565 & 0,441 & 64433,870 & 1,418 \\
\hline
\end{tabular}

Sumber: Output SPSS 24

Pada tabel di atas, nilai koefisien determinasinya sebesar 0,565 . Koefisien ini menjelaskan bahwa variable jumlah penduduk dan PDRB memeliki kontribusi sebesar 56,6\% terhadap variable kemiskinan di Provinsi Sumatera Utara tahun 2008-2017 dan sisanya $43,4 \%$ dipengaruhi oleh variabel lain yang mempengaruhi kemiskinan yang berada di luar penelitian ini.

\section{Pembahasan}

Berdasarkan hasil regresi yang diperoleh dari data yang diolah menggunakan SPSS 24 menjelaskan bahwa variable jumlah penduduk memiliki pengaruh yang positif dan signifikan terhadap variable kemiskinan di Provinsi Sumatera Utara tahun 2008 2017. dengan nilai koefisien sebesar 1,394 artinya apabila terjadi kenaikan jumlah penduduk sebesar 1 persen, maka akan menaikkan kemiskinan sebesar 1,349 persen.

Selanjutnya, hasil regresi yang diperoleh dari data yang diolah menggunakan SPSS 24 juga menunjukkan bahwa PDRB memiliki pengaruh yang negatif dan signifikan terhadap variabel kemiskinan di Provinsi Sumatera Uara tahun 2008-2013. Hal ini ditunjukkan dengan nilai koefisien sebesar $-2,368$, artinya apabila terjadi kenaikan PDRB sebesar 1 persen, maka 
akan menurunkan kemiskinan senesar 2,368 persen.

\section{SIMPULAN}

Berdasarkan hasil dan pembahasan penelitian mengenai pengaruh jumlah penduduk dan PDRN terhadap kemiskinan, dapat ditarik kesimpulan sebagai berikut:

a) variabel Jumlah penduduk me miliki pengaruh yang positif dan signifikan terhadap variabel kemiskinan di Provinsi Sumatera Utara tahun 2008-2017 dengan nilai $\mathrm{T}_{\text {hitung }}>\mathrm{T}_{\text {tabel }}$, yaitu 1,394 $>$ 0,711 pada taraf signifikansi sebesar 0,05

b) Variabel PDRB memiliki pengaruh yang negatif dan signifikan terhadap variable kemiskinan di provinsi Sumatera Utara tahun 2008-2017 dengan nilai $\mathrm{T}_{\text {hitung }}>\mathrm{T}_{\text {tabel }}$ yaitu 2,368 $>$ 0,711 pada taraf signifikansi sebesar 0,05

c) Variabel Jumlah Penduduk dan PDRB secara simultan memiliki pengaruh yang signifikan terhadap variable kemiskinan di Provinsi Sumatera Utara tahun 2008 2017 dengan $F$ hitung sebesar 4,549 > F tabel sebesar 4,46 pada taraf signifikansi sebesar 0,05 .

\section{DAFTAR PUSTAKA}

\section{A. Buku}

Arsyad, L. 2004. Ekonomi Pembangunan. Yogyakarta: UPP STIM YKPM.

BPS. 2013. Estimasi arameter Demograf: Tren Fertilitas, Mortalitas, dan Migrasi. Hasil Sensus Penduduk 2010. Jakarta

Dumairy. 2000. Perekonomian Indonesia. Jakarta: Erlangga.
Kuncoro, M. 2006. Ekonomi Kemiskian. Jakarta: Bumi Aksara.

Maipita,dkk. 2010. Ekonomi Kemiskinan. Medan: UNIMED.

Nanga. R. 2001. Makroekonomi: Masalah dana Kebijakan. Jakarta: PT. Raja Grafindo Persada.

Said, R. 2012. Pengantar Ilmu Kependudukan. Jakarta: Lembaga Penelitian dan Pengembangan Ekonomi dan Sosial.

Siregar, Hermanto dan Dwi Wahyuniarti. 2008. Dampak Pertumbuhan Ekonomi terhad ap Penurunan Jumlah Penduduk. Laporan Penelitian. Institut Pertanian Bogor.

Sukirno, Sadono. 2006. Makroekonomi: Teori Makro Ekonomi. Jakarta: Raja Grafindo Persada.

Tambunan, Tulus.T.H. 2003. Perekonomian Indonesia: Beberapa Masalah Penting. Jakarta: Galia Indonesia.

Todaro. Michael P. dan Stephen C.S. 2000. Pembangunan Ekonomi di Dunia Ketiga. Jakarta: Erlangga.

Widodo, T. 2006. Perencanaan Pembangunan: Aplikasi Komputer (Era Otonomi Daerah). Yogyakarta UPP STIM YKPN.

\section{B. Internet}

Suryawati, Criswardani. (2005). Memahami Kemiskinan Secara

Multidimensional.Jurnal.http://ww w.jmponline.net/Volume_8/Vol_0 8_No_03_2005.pdf.

www.bps.go.id

www.spssindonesia.com 